\title{
The specific distribution pattern of IKZFI mutation in acute myeloid leukemia
}

\author{
Xiang Zhang ${ }^{1,2} \mathbb{D}$, Xuewu Zhang ${ }^{1,2}$, Xia Li ${ }^{1,2}$, Yunfei Lv ${ }^{1,2}$, Yanan Zhu ${ }^{1,2}$, Jinghan Wang ${ }^{1,2}$, Jie Jin ${ }^{1,2^{*}}$ \\ and Wenjuan $\mathrm{Yu}^{1,2^{*}}$
}

\begin{abstract}
IKZF1 belongs to the IKAROS family of transcription factors, and its deletion/mutation frequently affects acute lymphoblastic leukemia. In acute myeloid leukemia, IKZFI deletion has been demonstrated recurrent, but whether IKZFI mutation also exists in AML remained largely unknown. Herein, we analyzed the IKZF1 mutation in AML. In our cohort, the frequency of IKZF1 mutation was 2.6\% (5/193), and 5 frameshift/nonsense mutations as well as 2 missense mutations were identified in total. Molecularly, IKZF1 mutation was absent in fusion gene-positive AML, but it was demonstrated as the significant concomitant genetic alteration with SF3B1 or bi-allele CEBPA mutation in AML. Clinically, two IKZF1, PTPN11 and SF3B1-mutated AML patients exhibited one aggressive clinical course and showed primary resistant to chemotherapy. Furthermore, we confirmed the recurrent IKZF1 mutation in AML with cBioPortal tool from OHSU, TCGA and TARGET studies. Interestingly, OHSU study also showed that SF3B1 mutation was the significant concomitant genetic alteration with IKZF1 mutation, indicating their strong synergy in leukemogenesis. In conclusion, IKZF1 mutation recurrently affected AML.
\end{abstract}

Keywords: IKZF1 mutation, Acute myeloid leukemia, Recurrence

IKZF1 belongs to the IKAROS family of transcription factors. It contains four zinc fingers at the N-terminal that directly bind to DNA at the core motif A/GGAAA and additional two zinc fingers at the C-terminal required for forming homo- and hetero-dimerization between different IKZF proteins [1]. DNA binding activity of IKZF1 can be enhanced by its dimerization, so both DNA-binding and dimer-forming defects alter IKZF1 function. IKZF1 deletions and mutations have been reported to affect B-cell precursor ALL and contribute to its poor prognosis [2]. IKZF1 alterations are less studied in AML. Recurrent $I K Z F 1$ deletions have been identified in AML [3, 4], but whether IKZF1 mutations affect AML

\footnotetext{
*Correspondence: jiej0503@zju.edu.cn; drwjyu1977@zju.edu.cn ${ }^{1}$ Department of Hematology, The First Affiliated Hospital, Zhejiang University School of Medicine, \#79 Qingchun Rd Zhejiang Province, Hangzhou 310003, China

Full list of author information is available at the end of the article
}

in general remains unknown. Herein, we analyzed $I K Z F 1$ mutation in AML.

A total of 193 adult AML patients, who subjected to TES, were retrospectively analyzed in our center (01/05/2018-29/02/2020), while APL was excluded. Among these patients, 100 were male and 93 were female, and the median age was 56 (range 18-82). A total of 169 patients were diagnosed with de novo AML, 10 with refractory/relapsed AML, 6 with MDS/AML, 5 with MLL (5 de novo cases), and 3 with MS/AML (1 de novo case, 2 refractory/relapsed cases). The panel of TES included 236 genes recurrently mutated in hematological malignancies, and TES was displayed by NovaSeq platform (Illumina). The average raw sequencing depth on target per sample was $\geq 1000$, and $\mathrm{VAF} \geq 1 \%$ was considered significant. For TES, 184 samples were collected from BM and 9 samples from PB. In addition, fusion gene screening for common rearrangements in AML was employed.

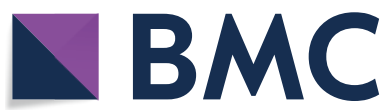

(c) The Author(s) 2020. Open Access This article is licensed under a Creative Commons Attribution 4.0 International License, which permits use, sharing, adaptation, distribution and reproduction in any medium or format, as long as you give appropriate credit to the original author(s) and the source, provide a link to the Creative Commons licence, and indicate if changes were made. The images or other third party material in this article are included in the article's Creative Commons licence, unless indicated otherwise in a credit line to the material. If material is not included in the article's Creative Commons licence and your intended use is not permitted by statutory regulation or exceeds the permitted use, you will need to obtain permission directly from the copyright holder. To view a copy of this licence, visit http://creativecommons.org/licenses/by/4.0/. The Creative Commons Public Domain Dedication waiver (http://creativeco mmons.org/publicdomain/zero/1.0/) applies to the data made available in this article, unless otherwise stated in a credit line to the data. 
IKZF1 mutation affected $2.6 \%(5 / 193)$ or $1.8 \%(3 / 169)$ of all AML patients or de novo AML patients from our cohort, respectively (Fig. 1a and Table 1). Totally, 7 different types of IKZF1 mutations were found, and 5 were frameshift or nonsense mutations, while 2 were missense mutations (Fig. 1b). Interestingly, IKZF1 mutation was absent in fusion gene-positive AML, while IKZF1 mutation co-occurred with PTPN11, SF3B1, bi-allelic CEBPA or WT1 mutation in our study
(Fig. 1c). Their association was further determined by Chi-square test with continuity correction, and OR was calculated. In 154 fusion gene-negative patients, we found that SF3B1 and bi-allelic CEBPA but not PTPN11 or WT1 mutations were the significant concomitant genetic alteration with $I K Z F 1$ mutation $(P<0.05$; OR $>1$ ) (Fig. 1d-f). In clinic, treatment response was evaluated in $4 / 5$ patients with IKZF1-mutated AML, and CR was achieved in 2 patients. Notably, 2 primary

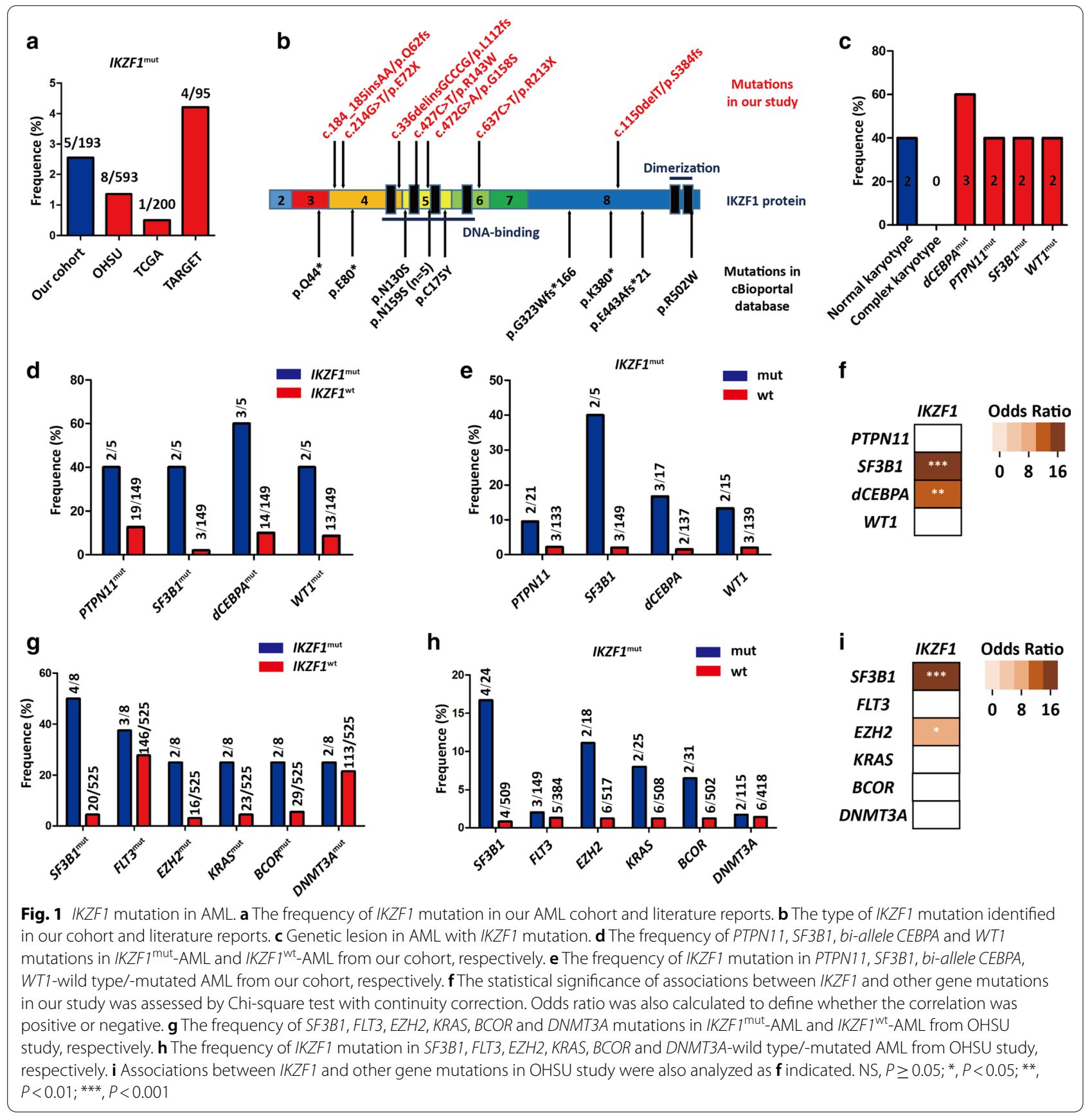




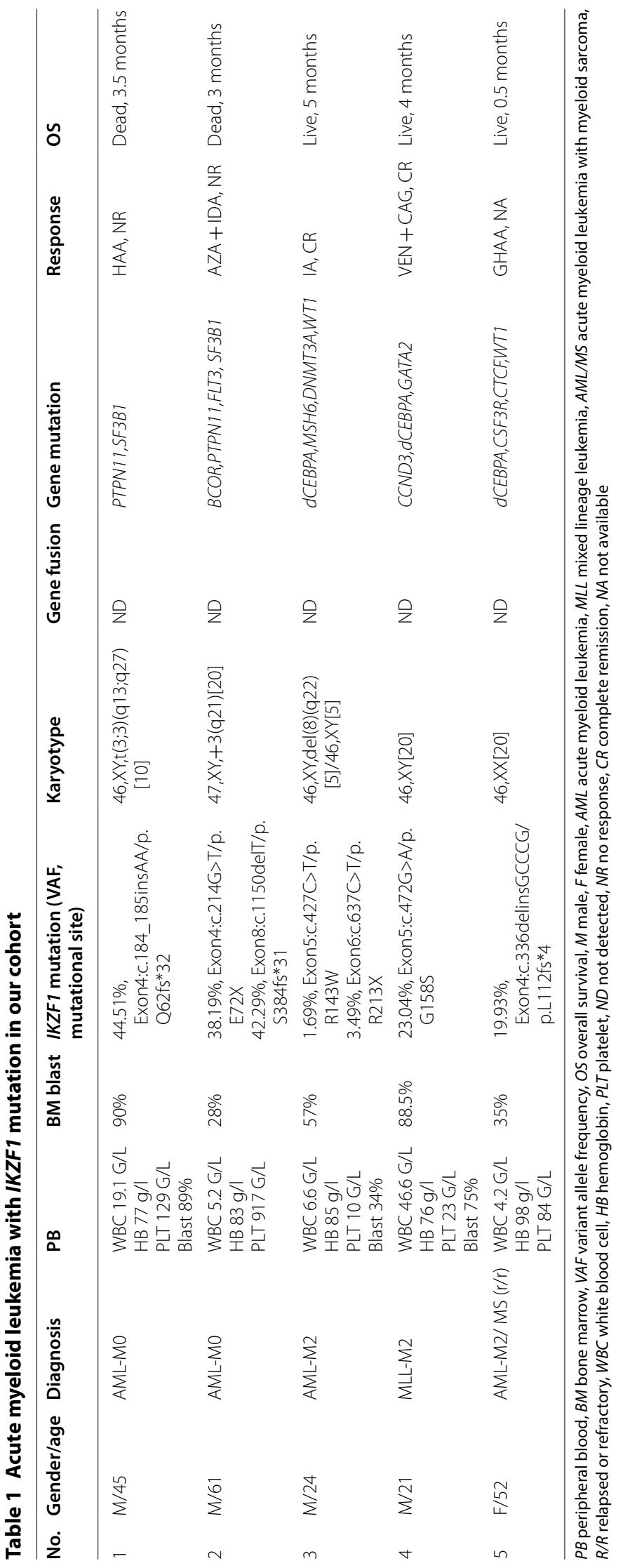


chemotherapy-resistant patients had IKZF1, PTPN11 and SF3B1-mutated AML, so this subtype of AML seemingly exhibited an aggressive clinical course. However, the impact of IKZF1 mutation in AML could not be determined in our study due to limited positive cases and short follow-up duration.

In addition to our study, we also used the cBioPortal tool to analyze the frequency of IKZF1 mutation in other three independent studies (OHSU [5], TCGA [6] and TARGET [7]). The frequency was $1.35 \%(8 / 593)$, $0.5 \%(1 / 200)$ and $4.21 \%(4 / 95)$, respectively, while the relatively high frequency in our study was possibly attributed to the criterion of enrollment and the limited cases (Fig. 1a). In total, 13 mutations were found in these studies, but there were no patients with 2 different mutations simultaneously (Additional file 1: Table S1). Of these 13 patients, 6 had frameshift or nonsense mutations and the rest 7 had missense mutations. IKZF1 ${ }^{\mathrm{N} 195 \mathrm{~S}}$ was a hotspot mutation with the frequency of $38.5 \%$ (5/13), but it was absent in COSMIC and our study (Fig. 1b). Due to limited positive cases in TCGA and solely pediatric cases in TARGET, we further analyzed the related genetic events of $I K Z F 1$ mutations in OHSU and found that SF3B1 and $E Z H 2$, but not KRAS, BCOR, FLT3 or DNMT3A mutations were the significant concomitant alteration with $I K Z F 1$ mutation (Fig. 1g-i). Remarkably, SF3B1 mutation appeared in both concomitant alteration lists of our study and OHSU, suggesting their strong synergy in leukemogenesis.

Compared to AML, IKZF1 alteration is well studied in ALL. Churchman et al. reported that IKZF1 alteration affected $25 \%$ of childhood and $44 \%$ of young adult pre-B-cell ALL, especially $B C R-A B L 1$-positive ALL with frequency of over $80 \%$. In ALL, the most common type of alterations in IKZFI is deletions, whereas IKZFI mutations accounted only $2.6 \%$ of childhood and $3.4 \%$ of young adult ALL. The latter were observed in $11.9 \%$ of $B C R-A B L 1$-negative and $2.2 \%$ of $B C R-A B L 1$-positive ALL cases [8]. The frameshift or nonsense mutations of IKZF1 often occurred at the $\mathrm{N}$-terminal or the region between DNA binding and dimerization domains, while missense mutations affected both domains. Consistently, IKZF1 mutations followed the same pattern in AML. Similarly to $I K Z F 1^{\mathrm{N} 159 \mathrm{~S}}$ in $\mathrm{AML}, I K Z F 1^{\mathrm{N} 159 \mathrm{Y}}$ is a hotspot mutation in ALL that affects its DNA binding domain. $I K Z F 1^{\mathrm{N} 159 Y_{-}}$ ALL exhibited one unique transcriptional profile characterized by downregulation of B-cell receptor and JAK-STAT signaling and upregulation of SALL1 [9]. Nevertheless, whether $I K Z F 1^{\mathrm{N} 159 \mathrm{~S}}$-AML could be defined as one independent subtype remains to be investigated.

In conclusion, besides of IKZF1 deletion, IKZF1 mutation is also recurrent in AML.

\section{Supplementary information}

Supplementary information accompanies this paper at https://doi. org/10.1186/s13045-020-00972-5.

Additional file 1: Table S1. The variant allele frequency of IKZF1 mutation in AML from cBioPortal database.

\section{Abbreviations}

ALL: Acute lymphoblastic leukemia; AML: Acute myeloid leukemia; APL: Acute promyelocytic leukemia; BM: Bone marrow; CR: Complete remission; MDS/AML: Myelodysplastic syndrome-transformed AML; MLL: Mixed lineage leukemia; MS/AML: Myeloid sarcoma with bone marrow infiltration; OR: Odds ratio; PB: Peripheral blood; TES: Targeted exome sequencing; VAF: Variant allele frequency.

\section{Acknowledgements}

Targeted-exome-sequencing was supported by Acornmed Company (Beijing, China). We thanked Bulat Abdrahimov for helping edit our English language.

\section{Authors' contributions}

XZ designed the experiments. X-WZ, XL, Y-FL, Y-NZ and J-HW collected and integrated clinical materials. $X Z$, JJ and W-JY integrated and analyzed all the data. XZ wrote the manuscript. JJ and W-JY revised the manuscript. All authors read and approved the final manuscript.

\section{Funding}

This work was supported by the National Natural Science Foundation of China (81800199, 81670124).

\section{Availability of data and materials}

All data generated or analyzed during this study are included in this published article.

\section{Ethics approval and consent to participate}

This study was approved by the ethical review committees of the First Affiliated Hospital to Zhejiang University School of Medicine.

Consent for publication

Written informed consent was obtained from this patient.

\section{Competing interests}

The authors declare that they have no competing interests.

\section{Author details}

${ }^{1}$ Department of Hematology, The First Affiliated Hospital, Zhejiang University School of Medicine, \#79 Qingchun Rd Zhejiang Province, Hangzhou 310003, China. ${ }^{2}$ Key Laboratory of Hematologic Malignancies, Diagnosis and Treatment, Zhejiang, Hangzhou, Zhejiang, China.

Received: 3 September 2020 Accepted: 29 September 2020 Published online: 20 October 2020

\section{References}

1. Marke R, van Leeuwen FN, Scheijen B. The many faces of IKZF1 in B-cell precursor acute lymphoblastic leukemia. Haematologica. 2018;103:565-74

2. Mullighan CG, Su X, Zhang J, Radtke I, Phillips LA, Miller CB, Ma J, Liu W, Cheng C, Schulman BA, et al. Deletion of IKZF1 and prognosis in acute lymphoblastic leukemia. N Engl J Med. 2009;360:470-80.

3. Milosevic JD, Puda A, Malcovati L, Berg T, Hofbauer M, Stukalov A, Klampfl T, Harutyunyan AS, Gisslinger H, Gisslinger B, et al. Clinical significance of genetic aberrations in secondary acute myeloid leukemia. Am J Hematol. 2012;87:1010-6.

4. de Rooij JD, Beuling E, van den Heuvel-Eibrink MM, Obulkasim A, Baruchel A, Trka J, Reinhardt D, Sonneveld E, Gibson BE, Pieters R, et al. 
Recurrent deletions of IKZF1 in pediatric acute myeloid leukemia. Haematologica. 2015;100:1151-9.

5. Cancer Genome Atlas Research N, Tyner JW, Tognon CE, Bottomly D, Wilmot B, Kurtz SE, Savage SL, Long N, Schultz AR, Traer E, Abel M, et al. Functional genomic landscape of acute myeloid leukaemia. Nature. 2018;562:526-31.

6. Ley TJ, Miller C, Ding L, Raphael BJ, Mungall AJ, Robertson A, Hoadley K, Triche TJ Jr, Laird PW, et al. Genomic and epigenomic landscapes of adult de novo acute myeloid leukemia. N Engl J Med. 2013;368:2059-74.

7. Bolouri H, Farrar JE, Triche T Jr, Ries RE, Lim EL, Alonzo TA, Ma Y, Moore R, Mungall AJ, Marra MA, et al. The molecular landscape of pediatric acute myeloid leukemia reveals recurrent structural alterations and age-specific mutational interactions. Nat Med. 2018;24:103-12.
8. Churchman ML, Low J, Qu C, Paietta EM, Kasper LH, Chang Y, PayneTurner D, Althoff MJ, Song G, Chen SC, et al. Efficacy of retinoids in IKZF1-mutated BCR-ABL1 acute lymphoblastic leukemia. Cancer Cell. 2015;28:343-56.

9. Li JF, Dai YT, Lilljebjorn H, Shen SH, Cui BW, Bai L, Liu YF, Qian MX, Kubota $Y$, Kiyoi $\mathrm{H}$, et al. Transcriptional landscape of B cell precursor acute lymphoblastic leukemia based on an international study of 1,223 cases. Proc Natl Acad Sci U S A. 2018;115:E11711-E117201720.

\section{Publisher's Note}

Springer Nature remains neutral with regard to jurisdictional claims in published maps and institutional affiliations.
Ready to submit your research? Choose BMC and benefit from:

- fast, convenient online submission

- thorough peer review by experienced researchers in your field

- rapid publication on acceptance

- support for research data, including large and complex data types

- gold Open Access which fosters wider collaboration and increased citations

- maximum visibility for your research: over $100 \mathrm{M}$ website views per year

At BMC, research is always in progress.

Learn more biomedcentral.com/submissions 